\title{
Clinical efficacy of amoxycillin/clavulanate in laparoscopically confirmed salpingitis
}

\author{
Obwegeser, J ; Kunz, J ; Wust, J ; Schar, G ; Steiner, R ; Buchi, W
}

\begin{abstract}
To test the efficacy and safety of amoxycillin/clavulanate (Augmenting 102 hospital patients with laparoscopically confirmed acute salpingitis were treated with paren-teral amoxycillin/clavulanate ( $1.2 \mathrm{~g}$ qid for three days) followed by oral amoxycillin/ clavulanate (two tablets of $625 \mathrm{mg}$ tid for a further six days). Bacteriological samples were obtained from the cervix uteri and the pouch of Douglas. One hundred patients were assessable for clinical outcome using several variables including pain scores. Amoxycillin/clavulanate alone was effective in 95 patients $(95 \%)$. Three patients $(3 \%)$ responded to amoxycillin/clavulanate with marked improvement but another antibiotic was subsequently added to their treatment regimen. Treatment failed in two patients. At follow-up two weeks after hospital discharge, three patients $(3.8 \%)$ had relapsed or were re-infected. Adverse drug events included one case of drug fever, one case of rash and one case of severe diarrhoea. Treatment was stopped in all three cases. Gastrointestinal reactions, mainly mild diarrhoea, were seen in 31 patients. No clinically relevant changes in haematological or clinical chemical indices were attributable to the amoxycillin/clavulanate treatment. We conclude that amoxycillin/clavulanate is a clinically effective and safe treatment for acute salpingitis
\end{abstract}

DOI: https://doi.org/10.1093/jac/24.suppl_b.165

Posted at the Zurich Open Repository and Archive, University of Zurich

ZORA URL: https://doi.org/10.5167/uzh-154635

Journal Article

Published Version

Originally published at:

Obwegeser, J; Kunz, J; Wust, J; Schar, G; Steiner, R; Buchi, W (1989). Clinical efficacy of amoxycillin/clavulanate in laparoscopically confirmed salpingitis. Journal of Antimicrobial Chemotherapy, 24(suppl B):165-176.

DOI: https://doi.org/10.1093/jac/24.suppl_b.165 


\title{
Clinical efficacy of amoxycillin/clavulanate in laparoscopically confirmed salpingitis
}

\author{
J. Obregeser, J. Kunz ${ }^{b}$, J. Wiaste, G. Schăre, R. Steiner ${ }^{a}$ and W. Büchi ${ }^{d}$ \\ 'University Hospital, Department of Gynaecology, Zürich; 'Pflegerinnenschule, Zürich; \\ 'Institute for Medical Microbiology, University of Zürich; 'Beecham Pharma, \\ Thörishous, Switzerland
}

\begin{abstract}
To test the efficacy and safety of amoxycillin/clavulanate (Augmentin), 102 hospital patients with laparoscopically confirmed acute salpingitis were treated with parenteral amoxycillin/clavulanate ( $1.2 \mathrm{~g}$ qid for three days) followed by oral amoxycillin/ clavulanate (two tablets of $625 \mathrm{mg}$ tid for a further six days). Bacteriological samples were obtained from the cervix uteri and the pouch of Douglas. One hundred patients were assessable for clinical outcome using several variables including pain scores. Amoxycillin/clavulanate alone was effective in 95 patients $(95 \%)$. Three patients (3\%) responded to amoxycillin/clavulanate with marked improvement but another antibiotic was subsequently added to their treatment regimen. Treatment failed in two patients. At follow-up two weeks after hospital discharge, three patients $(3.8 \%)$ had relapsed or were re-infected. Adverse drug events included one case of drug fever, one case of rash and one case of severe diarthoea. Treatment was stopped in all three cases. Gastrointestinal reactions, mainly mild diarrhoea, were seen in 31 patients. No clinically relevant changes in haematological or clinical chemical indices were attributable to the amoxycillin/clavulanate treatment. We conclude that amoxycillin/clavulanate is a clinically effective and safe treatment for acute salpingitis.
\end{abstract}

\section{Introduction}

Amoxycillin/clavulanate (Augmentin) is an association of amoxycillin and the $\beta$ lactamase inhibitor clavulanic acid (used as potassium clavulanate). The antimicrobial spectrum of amoxycillin is broadened by the clavulanic acid to include many $\beta$ lactamase-producing strains of both Gram-positive and Gram-negative species (Fuchs et al., 1983; Deforges, Soussy \& Duval, 1984; Slocombe et al., 1984). Amoxycillin/ clavulanate is active against Neisseria gonorrhoeae (including $\beta$-lactamase-producing strains) and Gram-positive and Gram-negative anaerobes (including Bacteroides fragilis). Both amoxycillin and clavulanate have been shown to penetrate readily into the pelvic peritoneal cavity (Houang, Colley \& Chapman, 1985).

The activity of amoxycillin/clavulanate against Chlamydia trachomatis in vivo is not yet well defined. Eradication of Ch. trachomatis by an appropriate dosage of amoxycillin has been demonstrated in men with gonococcal and non-gonococcal urethritis (Bowie, Alexander \& Holmes, 1981; Csángó, Gundersen \& Martinsen, 1985). Eradication from the cervix of pregnant women by amoxycillin was demonstrated in a recent

Correspondence to: Dr J. Obwegeser, Cantonal Hospital, Department of Gynaecology, CH-9007 St. Gallen, Switzerland. 
study (Crombleholme et al., 1988), where amoxycillin proved to be at least as effective as erythromycin. In-vitro activity of amoxycillin against Ch.trachomatis has been demonstrated by several investigators (Kramer, Cleeland \& Grunberg, 1979; Bowie et al., 1981; Hobson et al., 1982; Bowie, 1986; Orfila \& Haider, 1988).

Reports of the treatment of salpingitis with amoxycillin/clavulanate have been encouraging (Mayer, Jeschek \& Kowatsch, 1983; Ciraru-Vigneron et al., 1986). Monotherapy with amoxycillin/clavulanate would therefore seem to be an appropriate choice for the treatment of acute salpingitis.

\section{Patients and methods}

\section{Study population}

Patients admitted to the Department of Gynaecology of the University Hospital of Zürich from May 1984 to December 1987 with clinically suspected salpingitis were candidates for the trial and were subjected to laparoscopy.

Patients in whom the diagnosis of acute salpingitis could not be confirmed were excluded from further evaluation. Patients were also excluded from the trial if they had been treated with one or more antibiotics other than amoxycillin/clavulanate for less than $48 \mathrm{~h}$ before hospital admission (since this period of treatment would be too short to assess the response), if they had a history of penicillin allergy, if they were in renal or hepatic failure, or if they were suffering from immune deficiency.

\section{Treatment}

Treatment with amoxycillin/clavulanate was started promptly after laparoscopic confirmation of the diagnosis but before the results of culture were available. Initially amoxycillin/clavulanate $1.2 \mathrm{~g}$ iv was given qid until a marked improvement of the patient's condition occurred. During parenteral treatment the patients had strict bed rest. Therapy was then continued with amoxycillin/clavulanate tablets, $2 \times 625 \mathrm{mg}$ tid, until clinical recovery was almost complete or failure to respond to amoxycillin/ clavulanate made a change of therapy necessary.

\section{Clinical methods}

The laparoscopic techniques used and the criteria for the laparoscopic diagnosis and classification of the degree of severity of acute salpingitis were as described by Jacobson \& Westrōm (1969) and Ripa et al. (1980). The severity was classified as 'mild', 'moderate' or 'severe'. This rating was not used to determine the subsequent therapeutic regimen (Monif, 1982).

The clinical outcome was assessed by daily examination of the patient. Pain was assessed by two different scores. At the beginning and end of treatment we scored by bimanual examination of the pelvis (Scoring System A). To avoid repeated pelvic examination, abdominal examination was carried out for assessment during therapy (Scoring System B). The criteria used in Systems A and B and their score ranges are listed in Table I. The definitions for 'cure', 'markedly improved' and 'failure' are shown in Table II. Cases where therapy had to be stopped within three days because of an adverse event were considered unassessable for clinical outcome. A clinical follow-up 
Table I. Criteria of scoring systems A and B.

1. Scoring system A (bimanual examination of the pelvis)

(a) tenderness of the lower or whole abdomen

(b) rebound tenderness

Range of score (points)

(c) pain on motion of the cervix

(d) adnexal tenderness on left side

(c) adnexal tenderness on right side

$0-3$

$0-3$

$0-3$

$0-3$

Total

$0-3$

0-15

2. Scoring system $B$ (abdominal examination)
(a) abdominal pain
(b) abdominal pain when moving
(c) abdominal pain on pressure
Total
$0-3$
$0-3$
$0-3$
$0-9$

Range of score (points)

Pain ratings (points): 0, No pain.

1, Discomfort was not evident from the facial expression. Examiner had to ask if it hurt, and patient indicated that it did.

2. Discomfort was not evident but easily elicited by minimal pressure/motion.

3. Discomfort was evident and easily aggravated by minimal pressure/motion.

examination was done two weeks after the end of treatment, and pain was assessed by bimanual examination of the pelvis.

\section{Laboratory methods}

In each case specimens were taken from the cervical canal and the pouch of Douglas for bacteriological examination. Specimens intended for general bacteriological examination were transported in Stuart's Medium in the case of swabs and by the Portagerm System (Biomérieux, France) in the case of liquid specimens. Culture and identification of bacteria were performed aerobically and anaerobically according to standard procedures (Holdeman, Cato \& Moore, 1977; Lennette et al., 1985). Specimens for detection of $C h$. trachomatis were collected and examined by direct immunofluorescence staining as described in the MicroTrak Kit (SYVA Merck). Smears in which ten or more chlamydial organisms could be seen were reported as positive, and when two

Table II. Definitions for the assessment of pain.

\begin{tabular}{lll}
\hline & \multicolumn{1}{c}{ Scoring system A } & \multicolumn{1}{c}{ Scoring system B } \\
\hline $\begin{array}{l}\text { Cure } \\
\text { Markedly } \\
\text { improved }\end{array}$ & $\begin{array}{l}\text { 0-1 } \\
\text { More than 1, but not more than } \\
\text { one third of the score before } \\
\text { treatment }\end{array}$ & $\begin{array}{l}\text { More than 0, but not more than one } \\
\text { third of the score before treatment } \\
\text { Range: } 2-5\end{array}$ \\
$\begin{array}{l}\text { Score worse than "markedly } 1-3 \\
\text { improved" }\end{array}$ & \begin{tabular}{l} 
Score worse than "markedly improved" \\
\hline
\end{tabular} \\
\hline
\end{tabular}


to nine were seen as presumptively positive. Smears were not reported negative unless typical cells could be seen.

Haematological and clinical chemical investigations were carried out before and after treatment with amoxycillin/clavulanate to detect any adverse events.

\section{Results}

One hundred and two women entered the study. One hundred were assessable for clinical outcome. Their ages ranged from 17 to 47 years with a mean age of 26 years and a modal age of 23-24 years. The infection was classified as mild in $44(43 \cdot 1 \%)$ cases, moderate in $41(40.2 \%)$ cases and severe in $17(16.7 \%)$ cases. In $86(84.3 \%)$ patients the infection had been present for seven days or less, in $12(11.8 \%)$ patients the duration of symptoms was eight to fourteen days, and in four cases the duration was unknown (Table III).

Twenty patients had been pre-treated with an antibiotic. All of them had failed to respond after treatment for at least two days. The percentage of patients with positive bacteriological findings was somewhat higher in the group of patients without pretreatment $(68.3 \%$ vs $60-0 \%)$, but the difference was not statistically significant $(P<$ 0-05).

The dosages and durations of treatment with amoxycillin/clavulanate are shown in Table IV. The mean duration of parenteral treatment was 3.0 days, while that of the oral treatment was 6.4 days. The mean total duration of amoxycillin/clavulanate treatment (oral and parenteral) was 9.4 days.

The bacteriological findings are summarized in Table $\mathrm{V}$. The most frequent isolates were group B $\beta$-haemolytic streptococci. All of these were isolated from the cervix. Coagulase-negative staphylococci were isolated almost as often, but always from the pouch of Douglas. Of all isolated or detected organisms, $59.4 \%$ were found in the cervix, $49.5 \%$ in the pouch of Douglas, and $8.9 \%$ in both.

The clinical assessment of pain at the end of treatment is summarized in Table VI. When assessed by Score A, which is more sensitive than B, $80(80.0 \%)$ patients were free of pain and therefore classified 'cured'. Eighteen patients were 'markedly improved'. Treatment failed in two patients, and two were unassessable. All cases assessed 'markedly improved' are shown in Table VII. Fifteen of the 18 patients listed here did not need subsequent therapy, so that amoxycillin/clavulanate alone was effective in $95(95.0 \%)$ patients (Table VIII). Three patients improved markedly but subsequent therapy was necessary. In two cases a second antibiotic was necessary because of treatment failure. In two cases, one clinically cured and the other markedly improved, another antimicrobial agent was added because of a persistently high erythrocyte sedimentation rate (ESR). In three cases the initial therapy had to be changed because of an early adverse event. The eight cases in whom subsequent therapy was necessary are listed in Table $D X$.

The clinical courses as reflected by the leucocyte count, the ESR, the oral/axillary temperature and the pain scores A and B are shown in Figures 1 and 2. The percentages of patients in whom leucocyte count, ESR and the temperature were above normal at the various time points are shown in Figure 1. The mean pain scores $A$ and $B$, expressed as percentage of the maximal score, are given in Figure 2. At clinical followup 79 patients were assessable. Seventy-six (96.2\%) were still clinically cured. Three $(3.8 \%)$ had a relapse (or re-infection). Twenty-three patients were unassessable, either 
Tabte III. Duration of clinical symptoms before treatment

\begin{tabular}{lc}
\hline Duration (days) & No. of cases \\
\hline $1-3$ & $59(57.8 \%)$ \\
$4-7$ & $27(26.5 \%)$ \\
$8-14$ & $12(11.8 \%)$ \\
Unknown & $4(3-9 \%)$ \\
\hline
\end{tabular}

Table IV. Dosage and duration of treatment with amoxycillin/clavulanate

\begin{tabular}{llcc}
\hline Mode of & & \multicolumn{2}{c}{ Duration (days) } \\
treatment & Dosage regimen & mean & range \\
\hline Parenteral & 1.2 g qid & 30 & $1-6$ \\
Oral & 1250 mg tid & $6-4$ & $1-10$ \\
Parenteral + oral & see above & $9-4$ & $4-11$ \\
\hline
\end{tabular}

Table V. Results of the 68 positive findings (cervix and pouch of Douglas)



Table VI. Clinical assessment by pain scores A and B at end of treatment

\begin{tabular}{lcc}
\hline & \multicolumn{2}{c}{ No. of patients } \\
Assessment & score A & score B \\
(bimanual examination) & (abdominal examination) \\
\hline Cure & $80(80-0 \%)$ & $87(87-0 \%)$ \\
Markedly improved & $18(18-0 \%)$ & $11(11-0 \%)$ \\
Failure & $2(2-0 \%)$ & $2(2-0 \%)$ \\
Unassessable & 2 & 2 \\
\hline
\end{tabular}


Table VII. The cases assessed as 'markedly improved' at end of treatment

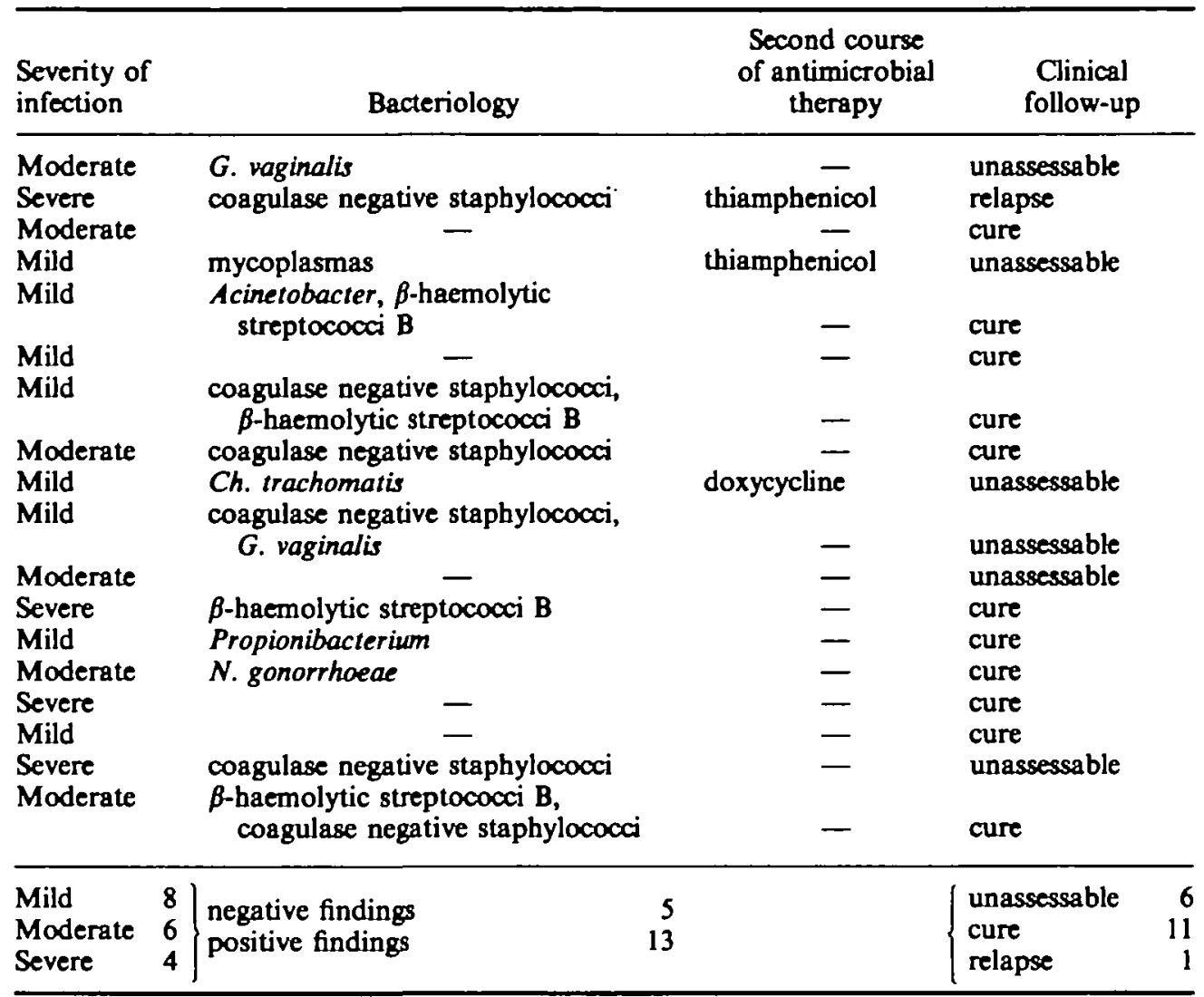

because they did not present for follow-up or, in three cases, were treated with an additional antibiotic.

Eight of the nine cases with chlamydial infections were 'cured' at the end of treatment, and one 'markedly improved' (perihepatitis with persistence of pain in the liver region). At follow-up all seven assessable patients were clinically cured.

Full haematological and clinical chemical investigations were done in all patients at the beginning and end of treatment. Slight elevations in serum transaminases were seen in some patients but were considered to be clinically insignificant; in all cases the transaminase levels remained within their normal ranges.

Table VIII. Efficacy of amoxycillin/clavulanate

\begin{tabular}{lc}
\hline Clinical outcome & No. of patients \\
\hline Amoxycillin/clavulanate alone effective & $95(95-0 \%)$ \\
Markedly improved, but subsequent therapy necessary & $3(3-0 \%)$ \\
Failure & $2(2-0 \%)$ \\
Unassessable & 2 \\
\hline
\end{tabular}




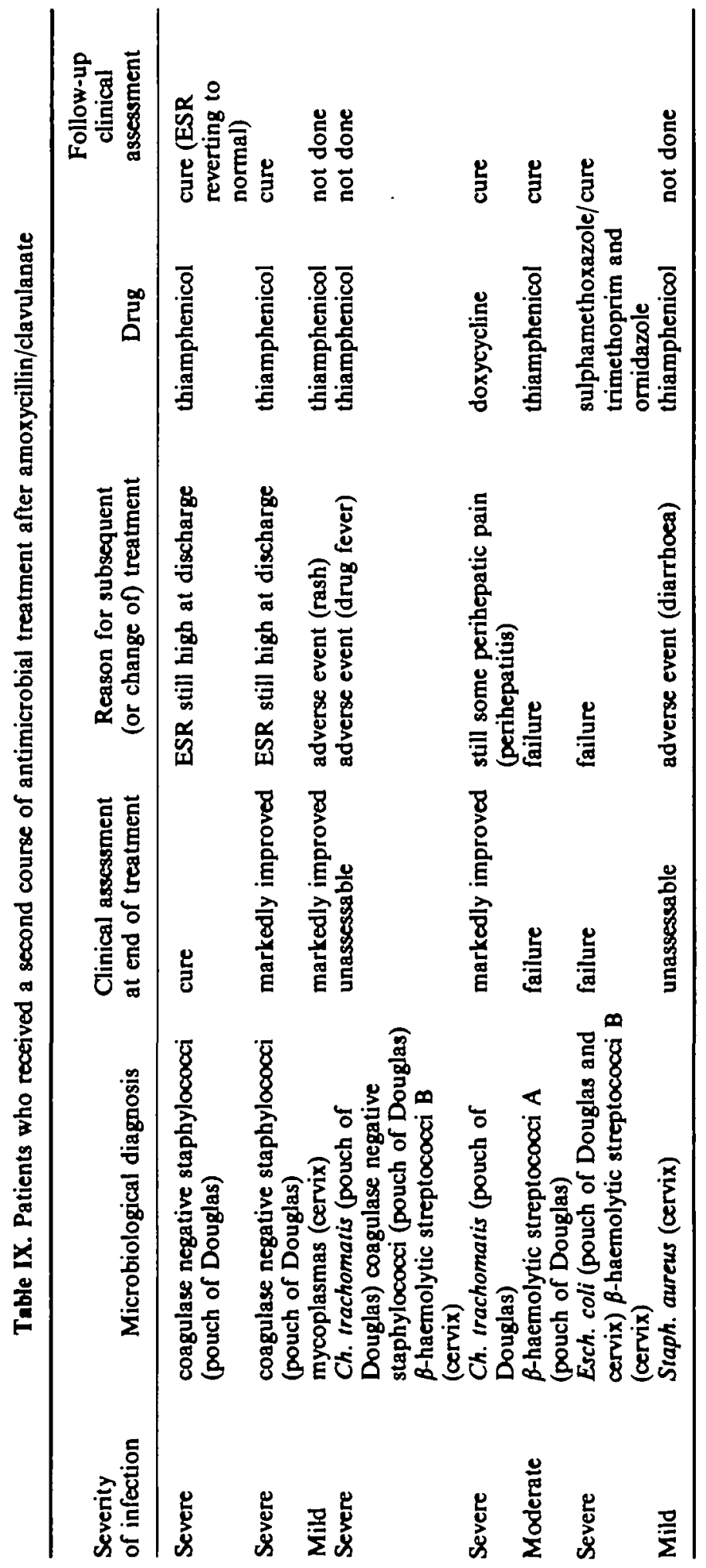




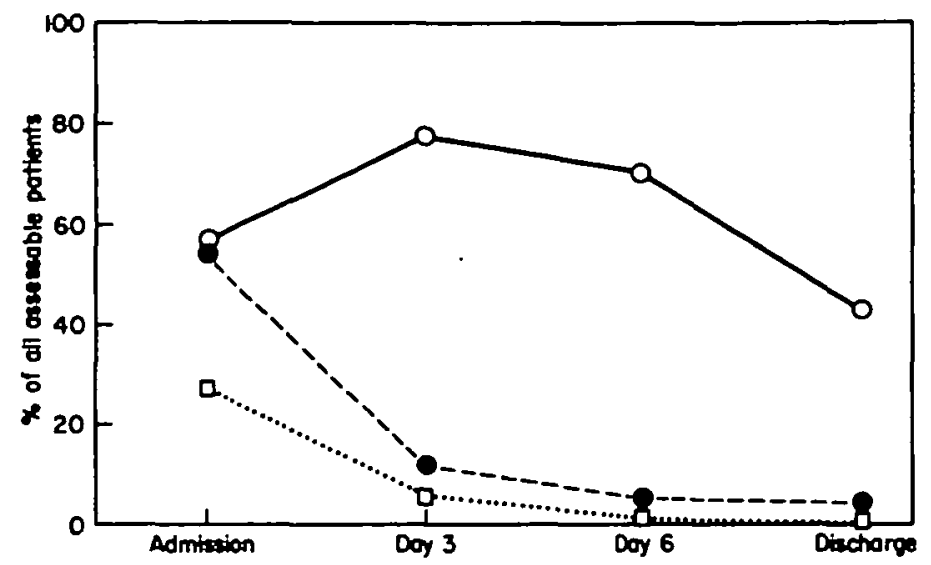

Figure 1. Clinical course: leucocyte count (LC), erythrocyte sedimentation rate (ESR) and temperature. ๑, LC $\geqslant 11,000 / \mathrm{mm}^{3} ; \mathrm{O}$, ESR $>20 \mathrm{~mm} / \mathrm{h} ; \mathrm{a}$, temperature $>38^{\circ} \mathrm{C}$.

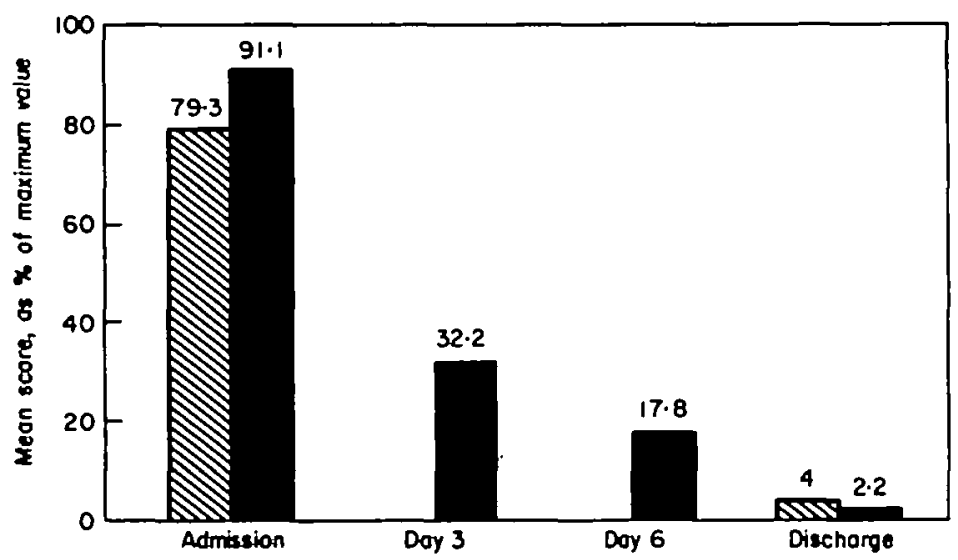

Figure 2. Clinical course: pain as assessed by scoring systems $A(\mathbb{N})$ and $B(\mathbb{D})$.

Table X. Adverse events

\begin{tabular}{|c|c|c|}
\hline Adverse event & No. of cases & $\begin{array}{c}\text { Therapy } \\
\text { discontinued }\end{array}$ \\
\hline Phlebitis & $48(47-0 \%)$ & - \\
\hline Drug fever & 1 & 1 \\
\hline Exanthems & 1 & 1 \\
\hline Severe diarrhoea & 1 & 1 \\
\hline Moderate diarrhoea & $12(11.8 \%)$ & - \\
\hline Mild diarthoea & $18(17.6 \%)$ & - \\
\hline Nausea + vomiting & 1 & - \\
\hline Nausea & 2 & - \\
\hline \multicolumn{3}{|l|}{ Mild to moderate } \\
\hline galactorrhoea & 2 & - \\
\hline Heartburn & 1 & - \\
\hline
\end{tabular}


The adverse events observed during the administration of amoxycillin/clavulanate are detailed in Table X. Amoxycillin/clavulanate therapy had to be discontinued in three patients, one with a drug fever, one with a rash and one with severe diarrhoea. Phlebitis was seen in $\mathbf{4 7 . 0 \%}$ of patients and was the most frequent adverse event. Since this problem was not uncommon in patients receiving no amoxycillin/clavulanate, it may have been associated with the venous cannulation systems used (Venflon and Abocath). Mild diarrhoea (up to three loose stools per day) was observed in $17.6 \%$ of patients and moderate diarrhoea (four to six loose stools per day) in $11.8 \%$.

\section{Discussion}

The diagnosis of acute salpingitis by clinical observation and haematological and clinical chemical investigations has been shown to be correct in only about $60 \%$ of cases (Jacobson \& Weström, 1969; Chaparro et al., 1978; Kolmorgen, Seidenschnur \& Wergien, 1978; Allen \& Schoon, 1983; Kunz \& Macciocchi, 1984; Wasserheit et al., 1986). In clinical studies, confirmation of the diagnosis of acute salpingitis by laparoscopy is therefore desirable. The fact that the haematological signs of acute salpingitis do not always match the laparoscopic picture is also demonstrated by our findings. In only $53.9 \%$ of our patients was the leucocyte count (LC) above $11,000 / \mathrm{mm}^{3}$. The erythrocyte sedimentation rate (ESR) was above $20 \mathrm{~mm} / \mathrm{h}$ in $57.0 \%$, and fever above $38.0^{\circ} \mathrm{C}$, in only $27.4 \%$ of patients. The laparoscopic assessment of the severity of infection gave the following results: $43.1 \%$ of the cases had a mild, $40.2 \%$ a moderate and $16.7 \%$ a severe infection.

The leading symptom of acute salpingitis is pain, which we assessed using two scoring systems (Table I). The same approach was chosen by Thompson et al. (1980). Since LC, ESR and temperature were not outside the normal range in a large number of hospital patients, pain was chosen as the main criterion to assess the state of recovery.

In this study we attempted not only to assess the clinical outcome at end of treatment, but also to follow the time course of recovery. When judged by the criteria 'cured' and 'markedly improved', as defined in Table II, 6.0\% of patients were already 'cured' (free of pain) at day three and $58.0 \%$ were 'markedly improved'. At day six, $42.8 \%$ were 'cured' and $48.0 \%$ 'markedly improved'.

For the final assessment of clinical outcome, pain score $A$, having greater sensitivity than pain score B, should preferably be used. Using A, 80-0\% of patients were categorized as 'cure', and $18.0 \%$ were 'markedly improved' (whereas $87.0 \%$ were 'cured' and 11.0\% 'markedly improved', using B) (Table VI). Assessment of pain by our scoring system is not, of course, absolutely objective. However, as shown above, the (objective) laboratory variables do not allow clearcut monitoring of the disease state. The ESR is the least reliable indicator of therapeutic success as its normalization lags behind the recovery suggested by other signs.

In $68(66.7 \%)$ of patients a bacterium could be isolated or Ch. trachomatis detected. Considering the care that was taken during withdrawal, transport and culture of the samples, and in view of the florid nature of the disease states in these patients, this number seems low. $\beta$-Haemolytic streptococci group B (23 isolates) and coagulasenegative staphylococci (22) were found most frequently. Their pathogenic role in acute salpingitis is, however, questionable.

In eight cases a second antibiotic was added to the treatment regimen (Table IX). In 
two of these patients pain had not decreased after three days of treatment. In a further patient, who had Ch. trachomatis infection and perihepatitis, antimicrobial chemotherapy was changed because the patient had persistent pain in the liver region. This case was not classified as a failure because pain had already markedly decreased during therapy with amoxycillin/clavulanate. The nine cases reported as Ch.trachomatis positive (Table V) do not include three cases categorized as presumably positive. Of all specimens subjected to direct immunofluorescence staining, no typical cells could be seen in $6.9 \%$ (thus not allowing an assessment). All the cases with Ch. trachomatis except one showed a good clinical response and no relapse on follow-up. We are aware that clinical success does not necessarily mean that the pathogens were eradicated (Sweet, Schachter \& Robbie, 1983; Martin, Pastorek \& Faro, 1986). These authors reported persistence of Ch.trachomatis after treatment with cephalosporins, but were unable to detect this organism after treatment with the extended-spectrum penicillins ticarcillin and piperacillin. Investigations carried out by Bowie et al. (1981) and Csángó et al. (1985) in urethritis in men showed that eradication of Ch. trachomatis by repeated administration of high doses of amoxycillin is possible. In a study by Crombleholme et al. (1988) amoxycillin was at least as effective as erythromycin in treating cervical infection with Ch.trachomatis in pregnancy. However, at present the addition of an antibiotic with proven activity against $C h$. trachomatis should be considered in cases where this pathogen has been isolated.

Phlebitis (47-0\% of cases) and gastrointestinal symptoms, mainly mild to moderate diarrhoea (29.4\%), were the predominant adverse events. Although the high incidence of phlebitis may have been associated with the frequent administration of antibiotic in high doses, phlebitis was also often observed in patients receiving no antibiotics. Therefore, the techniques of inserting iv catheters, and the material in the Venfion and Abocath systems we used, may have contributed significantly to the high incidence of phlebitis. In a series of studies at Swiss hospitals where amoxycillin/clavulanate was administered in a similar way, phlebitis was seen in only $15.3 \%$ of patients (Būchi \& Casey, 1988).

In one case amoxycillin/clavulanate therapy had to be stopped on the third day because of severe, persistent diarrhoea. Clostridium difficile was isolated, but no cytotoxin could be detected. The diarrhoea rapidly resolved following cessation of amoxycillin/clavulanate therapy, and vancomycin therapy was not necessary. In no other case with diarrhoea had therapy to be stopped, nor was the culture of a stool sample considered necessary. In the two patients with galactorrhoea, prolactin serum levels were normal and mammary pathology was excluded.

Overall, the $95 \%$ efficacy of amoxycillin/clavulanate alone in the treatment of acute salpingitis was very satisfactory (Table VIII). In spite of encouraging in-vivo results on the efficacy of amoxycillin against $C h$. trachomatis, at present an antibiotic with proven efficacy against this organism should be added in cases where its eradication is considered important.

\section{References}

Allen, L. A. \& Schoon, M. G. (1983). Laparoscopic diagnosis of acute pelvic inflammatory disease. British Journal of Obstetrics and Gynaecology 90, 966-8.

Bowie, W. R., Alexander, E. R. \& Holmes, K. K. (1981). Eradication of Chlamydia trachomatis from the urethras of men with nongonococcal urethritis by treatment with amoxicillin. Sexually Transmitted Diseases 2, 79-81. 
Bowie, W. R. (1986). In vitro activity of clavulanic acid, amoxicillin and ticarcillin against Chlamydia trachomatis. Antimicrobial Agents and Chemotherapy 29, 713-5.

Būchi, W. \& Casey, P. A. (1988). Experience with parenteral and sequential parenteral-oral amoxicillin/clavulanate (Augmentin) in hospitalized patients. Infection 16, 306-12.

Chaparro, M. V., Ghosh, S., Nashed, A. \& Poliak, A. (1978). Laparoscopy for the confirmation and prognostic evaluation of pelvic inflammatory disease. International Journal of Gynecology and Obstetrics 15, 307-9.

Ciraru-Vigneron, N., Bercau, G., Sauvanet, E., Nguyen Tan Lung, R., Felten, A., Leaute, J. B., et al. (1986). L'association amoxicilline-acide clavulanique comparce à la triple association ampicillin-gentamicine-métronidazole dans le traitement des infections utéro-annexielles stvères. Pathologie et Biologie 34, 665-8.

Crombleholme, W., Schachter, J., Sweet, R., Luft, J., Hansen, K., Jordan, C., et al. (1988). Amoxicillin vs erythromycin for treatment of Chlamydia trachomatis in pregnancy. In Program and Abstracts of the Twenty-eighth Interscience Conference on Antimicrobial Agents and Chemotherapy, Las Angeles, 1988. Abstract 591. American Society for Microbiology, Washington, DC.

Csángo, P. A., Gundersen, T. \& Martinsen, I. M. (1985). Effect of amoxicillin on simultaneous Chlamydia trachomatis infection in men with gonococcal urethritis: comparison of three dosage regimens. Sexually Transmitted Diseases 12, 93-6.

Deforges, L., Soussy, C. J. \& Duval, J. (1984). In vitro activity of the association of amoxycillin and clavulanic acid on anaerobic bacteria. Comparison with amoxycillin, lamoxactam and metronidazole. Pathologie et Biologie 32, 540-3.

Fuchs, P. C., Barry, A. L., Thornsberry, C., Gavan, T. L. \& Jones, R. N. (1983). In vitro evaluation of Augmentin by broth microdilution and disk diffusion susceptibility testing: regression analysis, tentative interpretive criteria, and quality control limits. Antimicrobial Agents and Chemotherapy 24, 31-8.

Hobson, D., Lee, N., Bushell, A. C. \& Withana, N. (1982). The activity of beta-lactam antibiotics against Chlamydia trachomatis in McCoy cell cultures. Chlamydial Infections (Mårdh, P.-A. Holmes, K. K., Oriel J. D., Piot, P. \& Schachter, J., Eds), pp. 249-52. Fernstróm Foundation Series 2. Elsevier Biomedical Press.

Holdeman, L. V., Cato, E. P. \& Moore, W. E. C. (Eds) (1977). Anaerobe Laboratory Manual, 4th edn. Virginia Polytechnic Institute and State University Anaerobe Laboratory, Virginia.

Houang, E. T., Colley, N. \& Chapman, M. (1985). Penetration of sulbactam-ampicillin and clavulanic acid-amoxicillin into the pelvic peritoneum. Antimicrobial Agents and Chemotherapy 28, 165-6.

Jacobson, L. \& Westrōm, L. (1969). Objectivized diagnosis of acute pelvic inflammatory disease. American Journal of Obstetrics and Gynecology 105, 1088-98.

Kolmorgen, K., Seidenschnur, G. \& Wergien, G. (1978). Diagnostik und Therapie des akuten Adnexprozesses beim Einsatz der Laparoskopie. Zentralblatt für Gynäkologie 100, 1103-9.

Kramer, M. J., Clecland, R. \& Grunberg, E. (1979). Activity of oral amoxicillin, ampicillin and oxytetracycline against infection with Chlamydia trachomatis in mice. Journal of Infectious Diseases 139, 717-9.

Kunz, J. \& Macciocchi, A. (1984). Acute salpingitis and thiamphenicol: A microbiologic and therapeutic study. Sexually Transmitted Diseases 11, 449-53.

Lennette, E. H., Balows, A., Hausler, W. J. \& Shadomy, H. J. (Eds) (1985). Manual of Clinical Microbiology, 4th edn. American Society for Microbiology, Washington, DC.

Martin, D. H., Pastorek, J. G. \& Faro, S. (1986). In-vitro and in-vivo activity of parenterally administered beta-lactam antibiotics against Chlamydia trachomatis. Sexually Transmitted Diseases 13, 81-7.

Mayer, H. O., Jeschek, H. \& Kowatsch, A. (1983). Augmentin in the treatment of urinary tract infection in pregnant women and pelvic inflammatory disease. Proceedings of the European Symposium on Augmentin, Scheveningen, 1982, pp. 207-17.

Monif, G. R. G. (1982). Clinical staging of acute bacterial salpingitis and its therapeutic ramifications. American Journal of Obstetrics and Gynecology 143, 489-95.

Orfila, J. \& Haider, F. (1988). In-vitro activity of amoxicillin-clavulanic acid (Augmentin) against Chlamydia trachomatis. Proceedings of the 6th Mediterranean Congress on Chemotherapy, Taormina, 1988. Abstract 288.

Ripa, K. T., Svensson, L., Treharne, J. D., Westrōm, L. \& Mårdh, P.-A. (1980). Chlamydia 
trachomatis infection in patients with laparoscopically verified acute salpingitis. American Journal of Obstetrics and Gynecology 138, 960-4.

Slocombe, B. Beale, A. S., Boon, R. J., Griffin, K. E., Masters, P. J., Sutherland, R., et al. (1984). Antibacterial activity in vitro and in vivo of amoxicillin in the presence of clavulanic acid. A Special Report, September/October 1984, Postgraduate Medicine $29-49$.

Sweet, R. L., Schachter, J. \& Robbie, M. O. (1983). Failure of beta-lactam antibiotics to eradicate Chlamydia trachomatis in the endometrium despite apparent clinical cure of acute salpingitis. Journal of the American Medical Association 250, 2641-5.

Thompson, S. E., Hager, W. D., Wong, W.-H., Lopez, B., Ramsey, C., Allen, S. D., et al. (1980). The microbiology and therapy of acute pelvic inflammatory disease in hospitalized patients. American Journal of Obstetrics and Gymecology 136, 179-86.

Wasserheit, J. N. Bell, T. A., Kiviat, N. B., Wolner-Hanssen, P., Zabriskie, V., Kirby, B. D., et al. (1986). Microbial causes of proven pelvic inflammatory disease and efficacy of clindamycin and tobramycin. Annals of Internal Medicine 104, 187-93. 